\title{
Utility and Flexibility Functions for Potential Customers in B2B E-Commerce Transactions
}

\author{
Boris Stavrovski \\ College of Staten Island, CUNY, New York, USA
}

\author{
Stiminc@aol.com
}

\begin{abstract}
One of the most evident premises for successful E-Commerce transaction should lie in as much detailed recognition of personal customers' differentiation as it becomes possible through the usage of multiple data resources available over the Internet. The methodical basis for the evaluation and subsequent utilization of all available data may be formed under the well known concepts of the utility theory. A new quantitative measure of the personal readiness for acceptable concessions in E-Commerce transaction (when the item under the consideration have been already chosen) is proposed in a form of so called flexibility functions for potential customers. Flexibility functions are shown to be useful also as a measure of the personal readiness for changes in a scale of attractiveness for all admissible items. The simple algorithms for the derivation of flexibility functions alongside with the particular examples from the commercial real estate field are further discussed.
\end{abstract}

Keywords: E-Commerce B2B transactions, flexibility functions, commercial real estate, utility theory.

\section{Background}

The development of electronic commerce with its numerous publicly available databases is enlarging the types of products and services that are becoming accessible over the Internet from simple items that are easily described by several main features (i.e., books, airplane tickets, cars etc.) to more complicated, less standardized products (i.e., real estate, medical and legal services). In that point the necessity of special arrangements - similar, for example, to those discussed in (Dearden, Harrison, \& Wright, 2000) is becoming clear for the researchers. The adequate description of the real preferences for all participants of E-Commerce transaction should be named as one of the most complicated and actual topics for investigations and discussions.

The theory and formal apparatus of quantitative evaluation of preferences for an individual is the subject of the utility theory. The main theoretical concepts of the utility theory have been described, for example in (Fishburn, 1988). The main formal tool of the theory - the utility function - mathematically describes the individual's preferences within the total scope of possible ways of resolution and of predictable results for problem in question.

The utility theory has good, established, practical and reliable algorithms (simple in 1-2 dimensional case but facing growing problems in multidimensional one - in fact all more or less complicated methods of

Material published as part of these proceedings, either on-line or in print, is copyrighted by Informing Science. Permission to make digital or paper copy of part or all of these works for personal or classroom use is granted without fee provided that the copies are not made or distributed for profit or commercial advantage AND that copies 1) bear this notice in full and 2) give the full citation on the first page. It is permissible to abstract these works so long as credit is given. To copy in all other cases or to republish or to post on a server or to redistribute to lists requires specific permission from the publisher at Publisher@InformingScience.org mathematical logical analysis has such problems) for generating utility functions' approximations with predetermined exactness of description for the individual's preferences. There are also some perspective approaches for distinctively more complicated cases like in (Brown, Santos, \& Banks, 1998) or (Giang, Shenoy, 2000), for example. It had been shown in (Chajewska, Koller, \& Ormoneit, 2001) 
that in some cases it is possible to reconstruct an individual's utility function by observing his/her behavior.

The practical aspect of the present research is connected with a commercial real estate transaction to be consummated over the Internet. The real experience in that kind of E-commerce B2B transactions is showing that the probability of a success in such a deal is mainly connected with some specific qualities of client's utility functions - his/her preparedness for compromises. It is natural to name the function, describing that quality, - the flexibility function. The concept of personal flexibility have been discussed, for example, in (Mendes, Mosley, \& Counsell, 2001), but even in most recent contributions to utility theory (Mirkin, 2001) there were no recollections between utility and flexibility functions.

The main goal of the present research is to introduce the flexibility function for an individual in its connection with his/her utility function and to show how the suggested methodical apparatus can be applied in a commercial real estate transaction over the Internet.

\section{Specific Features of E-commercial Real Estate Transactions}

The complexity of successful electronic transactions for such cases as commercial real estate deal originates from several sources:

- complexity of the product or of the service in question (i.e., real estate product has a multidimensional description, which includes dozens of parameters - location, property type, price range, taxes, vintage, condition, construction type, lot and building size, number and types of rooms, parking type and size, type of heating/cooling system, other facilities and amenities, type and condition of foundation, roof, floors, materials etc.);

- complexity of the agreement to be negotiated by the participants in order to finalize the transaction (i.e., real estate lease contract contains such negotiable parameters as - commencement and expiration dates, term, basic and additional rent with payment schedule, operating expenses, taxes, free rent period, rental escalation, loss factor, parking space allocation, security deposit, late payment penalties, repairs and alterations, insurance, services and utilities, rights of first offer, option to renew or cancel, non-disturbance, etc.);

- complexity and interdependence of the customer's preferences (which cannot be described in a single measure i.e. money) above the possible multiple values for all parameters, describing the product and the agreement to be negotiated;

- complexity of the search process, where the search domain and even the object to be found are not described in exact (quantitatively defined) terms, that causes the long and in some cases unsuccessful search process;

- complexity of the negotiation process where each participant, having their own interests, preferences and emotions, may generate the negative result simply because they were not willing to persevere in finding the variant which would deliver the necessary compromise or were not willing to invite a reputable and neutral third party to recommend a solution.

\section{Evaluation of Utility and Flexibility Functions for Potential Clients}

\section{The elementary algorithms}

The theory and formal apparatus of quantitative evaluation of preferences for an individual is the subject of so called utility theory. The main theoretical concepts of the utility theory have been described, for example in (Fishburn, 1988). The main formal tool of the theory - the utility function - mathematically describes the individual's preferences within the total scope of possible ways of resolution and of predictable results for problem in question. The utility theory has good, established, practical and reliable algo- 


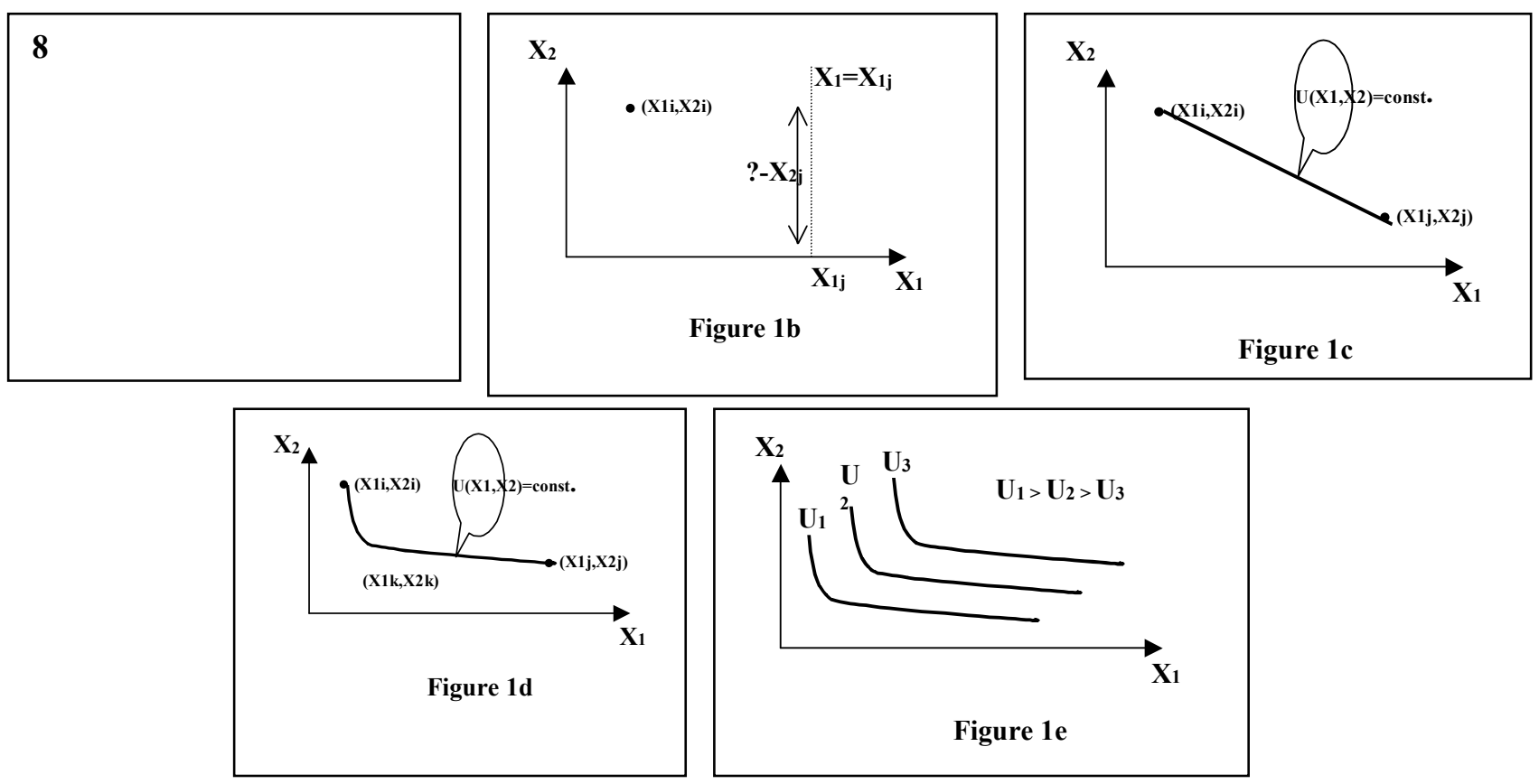

rithms (simple in 1-2 dimensional case but facing growing problems in multidimensional one - in fact all more or less complicated methods of mathematical logical analysis has such problems) for generating utility functions' approximations with predetermined exactness of description for the individual's preferences.

The idea of such a practical algorithm is fairly simple and may be illustrated on plane $(\mathrm{X} 1, \mathrm{X} 2)$ of the problem's description parameters, where each particular point (X1i, X2i) represents the particular result " $i$ " of the problem resolution. The interactive procedure of the utility function elaboration starts with the next question to the recipient: "If in comparison with the result (X1i,X2i) you should choose the other result " $\mathrm{j}$ " with one already fixed component X1j (let's say to be definite that X1j > X1i) - how will you pick the second component X2j to achieve the result which will be practically equal for you in its utility?" Geometrically the recipient should place the point on the vertical line $X 1=X 1 j$ thus designating the second coordinate $\mathrm{X} 2 \mathrm{j}$ of the point $(\mathrm{X} 1 \mathrm{j}, \mathrm{X} 2 \mathrm{j})$ with the same utility as the point $(\mathrm{X} 1 \mathrm{i}, \mathrm{X} 2 \mathrm{i})$ has for him.

When we are discussing the simplest case of a linear indifference curve (the curve of indifference is connecting the results of equal utility for the recipient) we will obtain the only available variant of such curve in the form of a straight line connecting two points (X1i, X2i) and (X1j, X2j). The hypothesis of linearity for indifference curve can be checked by asking the recipient to find the third point (X1k, X2k) which will be equivalent in its utility for any of the two points defined previously. If the point " $k$ " will be found on the same straight indifference curve - the hypothesis is correct, adversely we should switch to nonlinear approximations of the indifference curve.

Figures 1 a-e illustrates 5 sequential steps of interactive elaboration of the individual's utility function $\mathrm{U}(\mathrm{X} 1, \mathrm{X} 2)$, where on the plane $(\mathrm{X} 1, \mathrm{X} 2)$ of the object's parameters the object " $\mathrm{i}$ " with parameters (X1i,X2i) is shown first (FIG. 1a); then the recipient should choose the equally preferential object "j" with parameters $(X 1 j, X 2 j)$ by simply positioning the point $X 2 j$ on the direct line $X 1=X 1 j(F I G . ~ 1 b)$; connecting two points $(\mathrm{X} 1 \mathrm{i}, \mathrm{X} 2 \mathrm{i})$ and $(\mathrm{X} 1 \mathrm{j}, \mathrm{X} 2 \mathrm{j})$ we already may have the line of indifference for linear function $\mathrm{U}(\mathrm{X} 1, \mathrm{X} 2)$, where $\mathrm{U}(\mathrm{X} 1, \mathrm{X} 2)=$ const. (FIG. 1c); in the case of nonlinear $\mathrm{U}(\mathrm{X} 1, \mathrm{X} 2)$ we should proceed the same way with the third point $\mathrm{U}(\mathrm{X} 1 \mathrm{k}, \mathrm{X} 2 \mathrm{k})$ - thus obtaining the nonlinear curve of indifference (FIG. 1d); repeating the procedure several times we obtain the family of the such curves shown on FIG. 1e.

As a result of such procedure we only can produce an approximation of the utility function, because any mathematical method used for its allocation cannot guarantee that all other equivalent points will be exactly situated on the same indifference curve. However, in this case it is always possible to evaluate the 
potential errors of that approximation. When we are not satisfied with these potential errors the number of equivalent points in consideration should be simply enlarged thus making the quality of approximation better. Finally, we will be able to receive the approximation of the recipient's utility function in the compact form

$$
\mathrm{U}(\mathrm{X} 1, \mathrm{X} 2)
$$

with possibilities to determine its computational errors in each point.

The same step by step logic of comparison for pairs of the results should be used in multidimensional case. This procedure becomes even easier under a broadly used assumption that the utility function of a psychologically stable individual can be approximated with so called logistic curve

$$
\mathrm{U}(\mathrm{X})=\mathrm{a}+\mathrm{b} * \exp \{-\mathrm{c} * \mathrm{X}\}
$$

where $\quad a, b, c-$ designate the constant coefficients;

$$
\mathrm{X} \text {-designates the scalar result of the problem's resolution. }
$$

In the case when the recipient's preferences can be described independently from each other, the global utility function in multidimensional space will constitute the simple superposition of the scalar (marginal) functions and its formal description will be the result of multiplication of these marginal functions:

$$
\mathrm{U}(\mathrm{X} 1, \mathrm{X} 2, \ldots, \mathrm{Xn})=\mathrm{U}(\mathrm{X} 1) * \mathrm{U}(\mathrm{X} 2) * \ldots * \mathrm{U}(\mathrm{Xn}) \text {. }
$$

Again the validity of this assumption can be easily checked on the basis of additional questioning of the recipient.

\section{The spaces of the problem definition}

In the context of this research we will pay special attention to the specifics of the two very different spaces of definition for relevant transaction parameters. The first is the space $\Omega 1$ of the product's parameters, the elements of which X1 are constant for any chosen item and can not become the subject of negotiation but are the variables for the search procedure. The second is the space $\Omega 2$ of negotiable contract parameters, the elements of which X2 should become constant as a result of a compromise between buyer (customer) and seller (provider of services) after the contract has been signed by them. The elements of this space are the variables for both the search and the negotiation procedures. For exactness we will name the utility function $\mathrm{U}(\mathrm{X} 1, \mathrm{X} 2)$ the global one, and functions $\mathrm{U}(\mathrm{X} 1), \mathrm{U}(\mathrm{X} 2)$ - the marginal ones.

Geometrically the spaces $\Omega 1$ and $\Omega 2$ are also very different. The space $\Omega 1$ consists of the some limited number of the actual points $X 1 j, j \in(0, n)$, - that designates actual items - and of the unlimited number of the imaginary points X1i, that could exist in principle in a real life, but never were found as a result of any search procedures at the publicly available databases. The number " $n$ " is by itself the a-priori unknown function of the size for the space $\Omega 1$.

The example of such imaginary point is the so-called "ideal" item

$$
\mathrm{X} 01=\operatorname{Arg} \operatorname{Max} \mathrm{Ub}(\mathrm{X} 1), \quad \forall \mathrm{X} 1 \in \Omega 1,
$$

where $\operatorname{Arg} \varphi(Z)$ designates the function which is opposite to (defines the argument of) $\varphi(Z)$ :

$$
\mathrm{Z}=\operatorname{Arg} \varphi(Z),
$$

which may or (more probably) may not exist but conceptually and algorithmically is very useful.

We will use this ideal point as a starting (central) point of a search procedure and as a tool for an estimate for potential maximal level of the buyer's utility function $\mathrm{Ub}(\mathrm{X} 1)$ as well. 
The space $\Omega 2$ consists of the unlimited number of the points X2, and all of them are imaginary ones until the actual contract about one of the items $X 1 j, j \in(0, n)$, will be signed - at that moment the consequent point $X 2 j, j \in(0, n)$, also is becoming the actual one.

The third specific component of the problem to be considered is the actual time $\mathrm{T}$ with its limited interval of definition (To,Tk) between starting To and finishing Tk points of the time horizon in question. On comparatively short time intervals (i.e., months) we are not obliged to describe the time dependent behavior of the parameters

$$
\mathrm{X} 1=\mathrm{X} 1(\mathrm{~T}), \mathrm{X} 2=\mathrm{X} 2(\mathrm{~T})
$$

and of the spaces

$$
\Omega 1=\Omega 1(\mathrm{~T}), \Omega 2=\Omega 2(\mathrm{~T})
$$

as the variables on the interval (To,Tk), but when dealing with longer intervals (i.e., years or decades) it will be necessary to do it.

This will further complicate the problem in its mathematical aspect (the functions (1)-(3) are becoming time depending and all analytical and optimization procedures are much more resource intensive), but simultaneously will deliver new possibilities for decision making - as market timing for the buyer and the possibility to negotiate with the seller special additional payments (or discounts) in connection with time dependent arrangements and options.

One of the main principles of the decision making theory (it is better to have more strategic possibilities than not to) confirms at least the necessity not to overlook these possibilities. Thus in some cases so called static models (1)-(3) will be good enough because we are not interested in the analysis of time dependent features, but in other cases the dynamic specifics (4)-(5) should be involved in the consideration.

\section{The generation procedures}

Starting the generation procedure for the global utility function in the space $\Omega=\Omega 1 \cup \Omega 2$, it is necessary to articulate the difference between the general case (1) and the much less complicated case (3). In this second case the generation of the global utility function $\mathrm{U}(\mathrm{X} 1, \mathrm{X} 2)$ should be started by asking questions about equally preferable variants of parameters in the item space $\Omega 1$ and in the contract space $\Omega 2$ independently, then generating approximate marginal utility functions $\mathrm{U}(\mathrm{X} 1)$ and $\mathrm{U}(\mathrm{X} 2)$ and calculating the global utility function as the direct superposition of the two independent marginal utility functions

$$
\mathrm{U}(\mathrm{X} 1, \mathrm{X} 2)=\mathrm{U}(\mathrm{X} 1) * \mathrm{U}(\mathrm{X} 2) \text {. }
$$

Being the same in principle, the generation procedure for the global utility function $U(X 1, X 2)$ in the general case (1) comprises of asking questions about equally preferable variants of parameters in the item space $\Omega 1$ and in the contract space $\Omega 2$ simultaneously - that means the larger dimension of the space of definition and consequently the larger efforts necessary to obtain the result.

Mathematically the utility function generates the metrics over the discrete sets of the item's and of the contract's parameters thus creating the continuous and compact spaces with the same names and simultaneously delivering the possibility to use the all well established algorithmic apparatus of analysis, search and optimization specially constructed for that kind of the spaces.

The main practical goal of obtaining the utility functions for the participants is to obtain the "right" criteria for the search and negotiation procedures to follow, instead of the usually used universal measures as the price or the other money equivalents. In our case the price is only one of the space $\Omega 2$ components and that is up to the actual participants of the transaction to consider rather it is the particular component that is the most essential. Different buyers may decide this dilemma in very different ways. 
For example, there are two main types of buyers in typical real estate transactions. The first of them is buying the item as a place of residence and is mostly concerned with its consummation qualities. The sec-

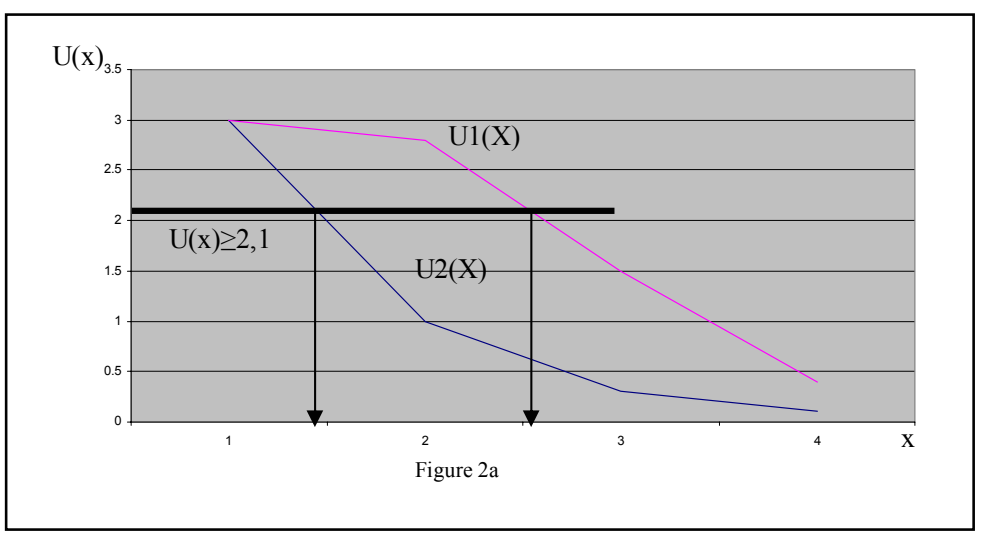
ond one considers the item as an investment opportunity and mostly concerns with its speculation potential, possible capital gains, rental income etc. The search and negotiation criteria for those two types of the buyers should not have very much in common. In particular, it is very essential for the last type of the buyer to use the dynamic utility models (4)-(5), because the time dependence becomes crucial for effectiveness and profitability of the transaction.

\section{Introduction of Flexibility Functions}

The utility function not only define the binary relation of preference in the space of the feasible alternatives (which delivers us the possibility to conclude that the result " $i$ " is more preferable than result " $j$ ") but implicate the quantitative measure of this preference thus making it possible to obtain the number which characterizes its comparable degree. Moreover we can evaluate how small variances of the argument will change the value of the utility function. This last quality gives us an unprecedented possibility to measure the personal readiness for a compromise in negotiations.

It is known from the calculus that the measure of function's response for small variations in its argument is its first derivative. From our point of view, after these considerations have been introduced it is logical enough to name "flexibility" the function

$$
\mathrm{F}(\mathrm{X})=\mathrm{dU}(\mathrm{X}) / \mathrm{dX}
$$

and to use this function for additional calculations in two related topics:

- as a measure of the personal readiness for changes in a scale of attractiveness for admissible items (search step of the procedure) - radius of the search domain;

- as a measure of the personal readiness for concession (negotiation step of the procedure) - radius of the negotiation domain.

\section{The search phase of the transaction}

To explain the idea of such usage, in Figure 2a two different variants of the typical utility curve U1(X) and $U 2(X)$ for a real estate item with a selling price $X$ are shown. We can definitely conclude that the person with the utility function $\mathrm{U} 1(\mathrm{X})$ is much more flexible and prepared for compromise than the person with the utility function $\mathrm{U} 2(\mathrm{X})$.

For example, if the minimal satisfying level of utility for both persons is established as

$$
\operatorname{Usat}(\mathrm{X}) \geq 2.1
$$

we will have

$$
\mathrm{U} 1(\mathrm{X}) \geq 2.1, \quad \forall \mathrm{X} \leq 2.6
$$

and

$$
\mathrm{U} 2(\mathrm{X}) \geq 2.1, \quad \forall \mathrm{X} \leq 1.4 \text {. }
$$

Therefore, if both persons are going to find the items that are admissible in the sense of the constraint 


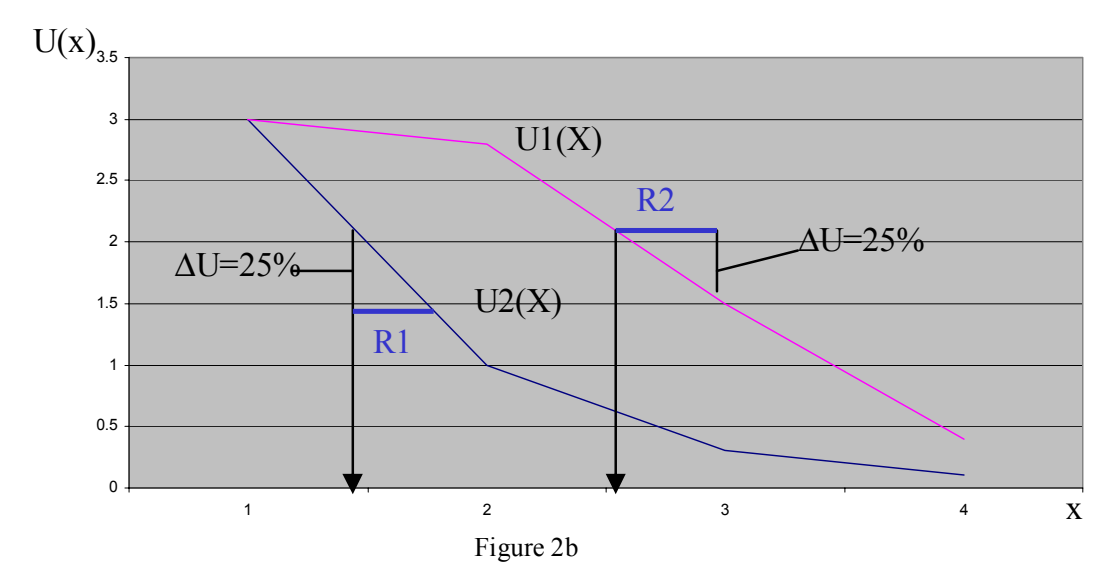

$\mathrm{U}(\mathrm{X}) \geq 2.1$,

the size (the double radius for the symmetrical case) of the search domain will be 2.6 units for the first person and only 1.4 units for the second one. The same logic is valid for the discussion of the negotiation domain's sizes.

To obtain the simple mathematical formula for the radius of search domain it is necessary to look in figure $2 \mathrm{~b}$, where the procedure of

the geometrical reconstruction of such radiuses $\mathrm{R} 1$ and $\mathrm{R} 2$ for two persons with the utility functions $\mathrm{U} 1(\mathrm{X})$ and $\mathrm{U} 2(\mathrm{X})$ respectively, are shown for the case when both of these persons have agreed upon the admissible level of the utility loss $\Delta \mathrm{U}=25 \%$.

Evidently,

$$
\begin{aligned}
& \mathrm{R}(\mathrm{X})=\Delta \mathrm{U} / \mathrm{F}(\mathrm{X}), \\
& \mathrm{F}(\mathrm{X})=\mathrm{dU}(\mathrm{X}) / \mathrm{dX}
\end{aligned}
$$

It is evident that here, as everywhere else here, all formulae are valid in their vector (i.e., component by component) form.

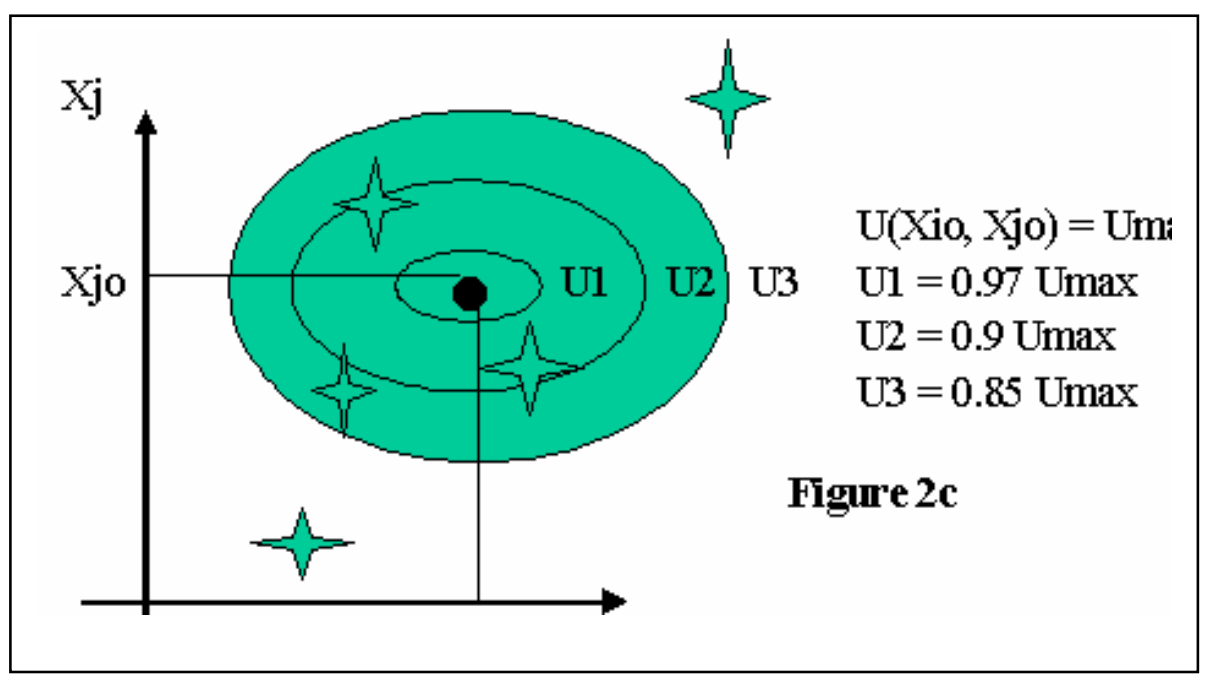

Formula (8) is correct for defining the radius of the search domain in the case when only one person's (the buyer's) utility function is taken into consideration. For example, from Figure $2 c$, where the lines of indifference for the buyer - in the form of ellipses for a bi-dimensional case $(\mathrm{Xi}, \mathrm{Xj})$ ) - are shown, and the admissible items are designated by the stars, it is clear that any admissible item is situated at the point of the maximal utility

(ideal item does not exist), even a 3\% loss of the utility does not generate any admissible variants, but a $15 \%$ loss of utility gives us three admissible items to be considered.

If we will include in the consideration the potential seller's flexibility, we should enlarge the radius of the search domain as it is illustrated in Figure2d.

Here the potential loss of 5\% in the seller's utility function has been found admissible and as a result a fourth star (the fourth admissible item) has been added to the list. In this case, with the goal not to loose any admissible items, we should define the radius of the search domain with the formula:

$$
\mathrm{Rb}(\mathrm{X})=\Delta \mathrm{Ub} / \mathrm{Fb}(\mathrm{X})+\mathrm{Rs}(\mathrm{X})
$$




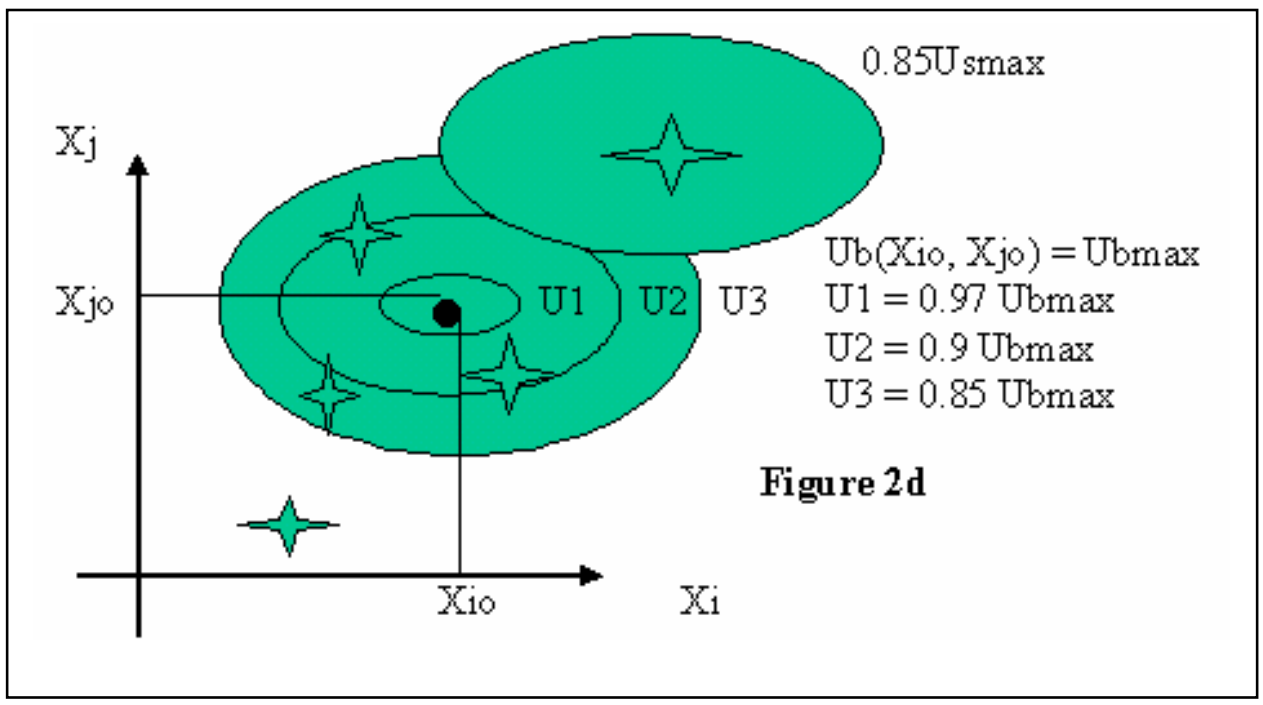

where $\mathrm{Rb}(\mathrm{X})$ designates the buyer's admissible radius of the search domain along the axis $\mathrm{X}$;

$\Delta \mathrm{Ub}$ designates the admissible level of the utility loss for the buyer;

flexibility.

$\mathrm{Rs}(\mathrm{X})$ designates an a-priori value of the similar admissible radius due to the potential seller's

Geometrically the surface described by the formula (9) may be treated as a hyper-sphere, with radius $\mathrm{Rb}(\mathrm{X})$, and that circumstance gives us the possibility to name the distance $\mathrm{Rb}(\mathrm{X})$ - the radius of the search domain. The central point of this hyper-sphere is situated at the point with coordinates

$$
\mathrm{X} 0=\operatorname{Arg} \operatorname{Max} \mathrm{Ub}(\mathrm{X}), \quad \forall \mathrm{X} \in \Omega .
$$

Combining (9) and (10), we can now define the search space $\Omega$ s as follows

$$
\Omega \mathrm{s}=\{\forall \mathrm{X} \in \Omega,[\mathrm{X} 0-\mathrm{Rb}(\mathrm{X})] \leq \mathrm{X} \leq[\mathrm{X} 0+\mathrm{Rb}(\mathrm{X})]\} .
$$

Using some algorithmic considerations (i.e., simplicity of the search procedure), we may also embed this hyper-sphere into the hypercube with the size of the one dimension $\mathrm{Rb}(\mathrm{X})$ along the axis $\mathrm{X}$. After the buyer's utility function $\mathrm{Ub}(\mathrm{X})$ and the subspace of the potential search

$$
\Omega s \subseteq \Omega
$$

have been determined, the search procedure can be defined as an unconstrained maximization of said utility function in the spaces of the item and contract parameters:

$$
\mathrm{Xad} 1=\operatorname{Arg} \operatorname{Max} \mathrm{Ub}(\mathrm{X}), \quad \forall \mathrm{X} \in \Omega \mathrm{s} \subseteq \Omega,
$$

where Xad1 designates the parameters of the item entitled to be admissible in the first list of the search results. Evidently, in the case when the procedure (13) has been unsuccessfully finished and the first list contains no items, it is necessary to suggest to the buyer some changes in preferences (the possible losses $\Delta \mathrm{Ub}$ ) and then the problem (13) will acquire the next form

$$
\mathrm{Xad} 1=\operatorname{Arg}\{\mathrm{Ub}(\mathrm{X}) \geq[\operatorname{Max} \mathrm{Ub}(\mathrm{X})-\Delta \mathrm{Ub}]\}, \forall \mathrm{X} \in \Omega \mathrm{s} \subseteq \Omega .
$$

The problem (14) will always have at least one nontrivial result in case when $\Delta \mathrm{Ub}$ is sufficient and that is a very essential distinction from (13). It is necessary to mention that the size of the search domain $\Omega \mathrm{s}(\mathrm{X})$ becomes simultaneously and automatically larger as a result of (9). If the buyer disagrees with the suggested changes in the preferences, the whole procedure should be cancelled as an unsuccessful one.

Traditionally, similar systems are paying too much attention to the buyer's budget limitations, automatically excluding all variants which are not affordable to the buyer. Our experience shows that this position 
is not always correct. First - after the serious negotiation the seller can often agree to concessions that will resolve the problem; and second - other features of the transaction (besides the price) can be extremely preferential for the buyer so that the additional money will be found - as a result of more creative financing.

Nevertheless, when such budget limitations, for example,

$$
\mathrm{B}(\mathrm{X}) \leq \mathrm{Blim},
$$

(where Blim designates the available funds) are known from the preliminary contacts with the buyer, the problems (13)-(14) can be easily transformed in the problem of maximization of the constrained utility function in the spaces of the item and contract parameters under said buyer's budget affordability limitations:

$$
\begin{aligned}
& \mathrm{Xad} 1=\operatorname{Arg} \operatorname{Max} \mathrm{Ub}(\mathrm{X}), \forall \mathrm{X} \in \Omega \mathrm{s} \subseteq \Omega, \mathrm{B}(\mathrm{X}) \leq \mathrm{Blim}, \\
& \mathrm{Xad} 1=\operatorname{Arg}\{\mathrm{Ub}(\mathrm{X}) \geq[\operatorname{Max} \mathrm{Ub}(\mathrm{X})-\Delta \mathrm{Ub}]\}, \forall \mathrm{X} \in \Omega \mathrm{s} \subseteq \Omega, \mathrm{B}(\mathrm{X}) \leq \mathrm{Blim} .
\end{aligned}
$$

From the point of view of the utility theory the buyer's budget limitations are already included in utility function $\mathrm{Ub}(\mathrm{X})$ and should not be treated in the form (13')-(14').

In principle the specifics for the dynamic variant of the optimization problem (13')-(14') can also be interpreted as a feature that is already included in previously described formalization. In this case the moment $\mathrm{Tt} \in(\mathrm{To}, \mathrm{Tk})$ of the transaction's finalization should be considered as an additional element of the contract space $\Omega 2$, and the same is true for additional option premiums $\mathrm{P}(\mathrm{Tt})$ to be paid for the time difference ( $\mathrm{Tt}-\mathrm{To}$ ), that becomes a very essential part of the problem. Nevertheless, with the purpose to be as precise as possible, we will also give the special detailed variant of (13')-(14') for that case as follows

$\{\mathrm{Xad} 1, \mathrm{P}(\mathrm{Tt}), \mathrm{Tt}\}=\operatorname{Arg} \operatorname{Max}\{\mathrm{Ub}[\mathrm{X}(\mathrm{T}), \mathrm{P}(\mathrm{T}), \mathrm{T}]\}$,

$\forall \mathrm{X}(\mathrm{T}) \in \Omega \mathrm{s}(\mathrm{T}) \subseteq \Omega(\mathrm{T}), \mathrm{B}[\mathrm{X}(\mathrm{T})] \leq \mathrm{B}(\mathrm{T}), \mathrm{T} \in(\mathrm{To}, \mathrm{Tk})$

and

$\{\mathrm{Xad1}, \mathrm{P}(\mathrm{Tt}), \mathrm{Tt}\}=\operatorname{Arg}\{\mathrm{Ub}[\mathrm{X}(\mathrm{T}), \mathrm{P}(\mathrm{T}), \mathrm{T}] \geq[\mathrm{Max} \mathrm{Ub}[\mathrm{X}(\mathrm{T}), \mathrm{P}(\mathrm{T}), \mathrm{T}]-\Delta \mathrm{Ub}(\mathrm{T})]\}$,

$\forall \mathrm{X}(\mathrm{T}) \in \Omega \mathrm{s}(\mathrm{T}) \subseteq \Omega(\mathrm{T}), \mathrm{B}[\mathrm{X}(\mathrm{T})] \leq \mathrm{B}(\mathrm{T}), \mathrm{T} \in(\mathrm{To}, \mathrm{Tk})$.

Evidently, each and every of aforementioned theoretical results, connected with the buyer's utility function Ub, is possible to implicate to the seller's utility function Us as well. The only (but very essential) difference is connected with the space of the definition for the seller's utility function - this function can only be defined for all $\mathrm{X} 2 \in \Omega 2$, because parameter X1 becomes constant for any particular seller.

\section{The negotiation phase of the transaction}

It is logical enough to start the description of the negotiation segment of the procedure from the definition for the admissible negotiation domain $\Omega \mathrm{n}$ - which is similar to the search domain $\Omega \mathrm{s}$, defined earlier. It is evident, that $\Omega \mathrm{n} \subseteq \Omega 2$. The goal of the negotiation is to find some point $\mathrm{X} 2 \in \Omega \mathrm{n}$, where both participants (the buyer and the seller) would obtain the result, which in some sense, will be good enough for both of them to approve the closing of the transaction. We are going to describe the results in the terms of the buyer's $\mathrm{Ub}(\mathrm{X} 2)$ and of the seller's $\mathrm{Us}(\mathrm{X} 2)$ utility functions for the each pair of buyer/seller \#j, $\mathrm{j} \in(1, \mathrm{~m})$. The "best" imaginary points Xboj for the buyer and Xsoj for the seller may be found as follows

$$
\mathrm{Xboj}=\operatorname{Arg} \operatorname{Max} U b(X), \forall X \in \Omega 2,
$$


Utility and Flexibility Functions

$$
\begin{aligned}
& \text { Xsoj }=\operatorname{Arg} \operatorname{Max} U s(X), \forall X \in \Omega 2, \\
& \operatorname{Arg} \varphi(Z) \equiv Z,
\end{aligned}
$$

and should be considered as the central points of the domains $\Omega$ nbj (for the buyer) and $\Omega$ nsj (for the seller), the locations where both parties are prepared to negotiate.

We have already seen how the flexibility of the buyer $\mathrm{Fb}(\mathrm{X})$ defines the radius of the search domain. Radiuses of the buyer's Rnbj(X2) and seller's Rnsj(X2) negotiation domains for the each pair of buyer/seller $\# \mathrm{j}, \mathrm{j} \in(1, \mathrm{~m})$, should be defined similarly as follows

$$
\begin{aligned}
& \operatorname{Rnbj}(X 2)=\Delta U b j / F b(X 2), \forall X 2 \in \Omega 2, \\
& \operatorname{Rnsj}(X 2)=\Delta U s j / F s j(X 2), \forall X 2 \in \Omega 2, j \in(1, m) .
\end{aligned}
$$

It is appropriate to mention here that the coordinates Xboj and the radiuses $\mathrm{Rnbj}(\mathrm{X} 2)$ will have different values for the different numbers $\mathrm{j}, \mathrm{j} \in(1, \mathrm{~m})$, - because, for each such special case, the values X1j (the description of the item in question) will also be different.

Finally, combining (15) and (16) we define $\Omega$ nj for the pair of buyer/seller $\# \mathrm{j}, \mathrm{j} \in(1, \mathrm{~m})$, as follows

$$
\begin{gathered}
\Omega n j=\Omega n b j \cap \Omega n s j, \\
\Omega n b j=\{\forall X 2 \in \Omega 2,[X b o j-\operatorname{Rnbj}(X 2)] \leq X 2 \leq[X b o j+\operatorname{Rnbj}(X 2)]\},(17) \\
\Omega n s j=\{\forall X 2 \in \Omega 2,[X s o j-\operatorname{Rnsj}(X 2)] \leq X 2 \leq[X s o j+\operatorname{Rnsj}(X 2)]\}, j \in(1, m) .
\end{gathered}
$$

The principal theoretical tool for analyzing negotiations is the game theory, which applies to any situation where the outcome of one person's actions or decisions depends, in a definite way, on the actions or decisions of others. In this sense, every negotiation is a game. At this point we have all the elements of the game theory model presented:

- two players (the buyer and the seller) who can make various agreements X2 (outcomes) derived from the space of outcomes $\Omega \mathrm{n}$;

- each player is presumed to be able to evaluate the attractiveness of every conceivable outcome, including the possibility of no agreement, with their criteria Ub (X2) and Us (X2) defined in the space of outcomes $\Omega \mathrm{n}$;

- the description (17) of all outcomes $X 2 \in \Omega$, which are in principle available for their choice;

- $\quad$ the rules of the negotiation game, that presume the zero results for both buyer and seller if they will be enable to find a compromise in the form of X2 $\in \Omega$ n (so called BATNA- Best Alternative To a Negotiated Agreement).

Now some theoretical concepts of the game theory may become very useful. It seems reasonable to assume that no party will accept an agreement that leaves this party in a worse position than its BATNA. This assumption is known as individual rationality. Therefore, the utility of each party's BATNA places a lower bound on the utility that each party must realize from the negotiated settlement. Minimum possible payoffs are defining the disagreement point - point $(0,0)$.

A second reasonable criterion of a negotiated agreement is that all potential gains should be realized. In other words, it should not be possible to make some parties better off while making the other party worse off. Therefore, an agreement that satisfies this criterion is said to be efficient. The efficient agreements correspond to points that lie on the northeastern boundary of the negotiation set, which boundary is called the Pareto curve. 
Any solution that is both individually rational and efficient (belongs to the Pareto curve) can be called reasonable, however there are typically many such solutions. Which of these solutions are most reasonable and may, therefore, be recommended as a basis for a buyer/seller compromise? We can suggest several answers to this question.

First, the equal splitting of the difference $\nabla \times 2$ between the offering and the asking values of the parameter $\mathrm{X} 2$ or the same equal splitting, but scaled in the utilities $\mathrm{Ub}(\nabla \mathrm{X} 2)$ and $\mathrm{Us}(\nabla \mathrm{X} 2)$.

Second, minimization of the maximum possible loss in the values of $\mathrm{Ub}(\mathrm{X} 2)$ and $\mathrm{Us}(\mathrm{X} 2)$ as a result of the choice Xo2:

$\mathrm{Xo2}=\operatorname{Arg} \operatorname{Min} \operatorname{Max}\{[\mathrm{Ub}(\mathrm{X} 2)-\mathrm{Ub}(\mathrm{Xo2})],[\mathrm{Us}(\mathrm{X} 2)-\mathrm{Us}(\mathrm{Xo} 2)]\}, \forall \mathrm{X} 2 \in \Omega \mathrm{p}$,

where $\Omega$ designates the Pareto curve.

Third (The Nash Equilibrium), the result of the next optimization problem:

$$
\mathrm{Xo} 2=\operatorname{Arg} \operatorname{Max}\{\mathrm{Ub}(\mathrm{X} 2) * \mathrm{Us}(\mathrm{X} 2), \forall \mathrm{X} 2 \in \Omega \mathrm{p}\} .
$$

It is well known from the game theory that there always exists the unique solution for problem (19) possessing the following properties:

- independence of the equivalent utility representations (measuring the temperature by Celsius or Fahrenheit does not change its actual value);

- $\quad$ symmetry (the solution should not distinguish between the players if the model does not);

- independence of irrelevant alternatives (this property allows the possibility to narrow the original negotiation space $\Omega \mathrm{n}$ to a smaller space $\Omega \mathrm{p}$, without changing the outcome);

- Pareto optimality.

To finalize the theme of dynamic specifics, we can rewrite equation (19) in its equivalent dynamic form as follows

$$
\begin{aligned}
\{\mathrm{Xo} 2, \mathrm{P}(\mathrm{Tt}), \mathrm{Tt}\}= & \operatorname{Arg} \operatorname{Max}\{\mathrm{Ub}[\mathrm{X} 2(\mathrm{~T}), \mathrm{P}(\mathrm{T}), \mathrm{T}] * \mathrm{Us}[\mathrm{X} 2(\mathrm{~T}), \mathrm{P}(\mathrm{T}), \mathrm{T}]\}, \\
& \forall \mathrm{X} 2(\mathrm{~T}) \in \Omega \mathrm{p}(\mathrm{T}), \mathrm{T} \in(\mathrm{To}, \mathrm{Tk}) .
\end{aligned}
$$

\section{An Example of a Commercial Real Estate Transaction System}

As an example of a practical implementation of those formal constructions the system (Stavrovski, 1999) for doing commercial real estate business over the Internet can be shortly described.

Figure 3 illustrates a greatly simplified block diagram of the primary elements of the computer-based system which is employed for carrying out the commercial real estate transaction over the Internet. The computer-based system includes a potential buyer/consumer computer terminal 1 with its communication means (i.e., modem and phone line with possibilities to be connected with other parts of the system through the Internet), a plurality 2 of publicly available databases hosted over the Internet with its communication means, a plurality 3 of potential sellers/providers of services computer terminals with its communication means, a plurality 4 of due diligence agents computer terminals with its communication means and finally a central operating block 5 with its communication means, whose activities are designated for combining the system to function as a whole creation rather than a simple collection of the independent elements.

The mission of the whole system may be described as the consequence of steps:

- after establishing the initial interactive contact with the potential buyers/ customers 1 through the communication means over the Internet the system analyzes their actual preferences in the space of 


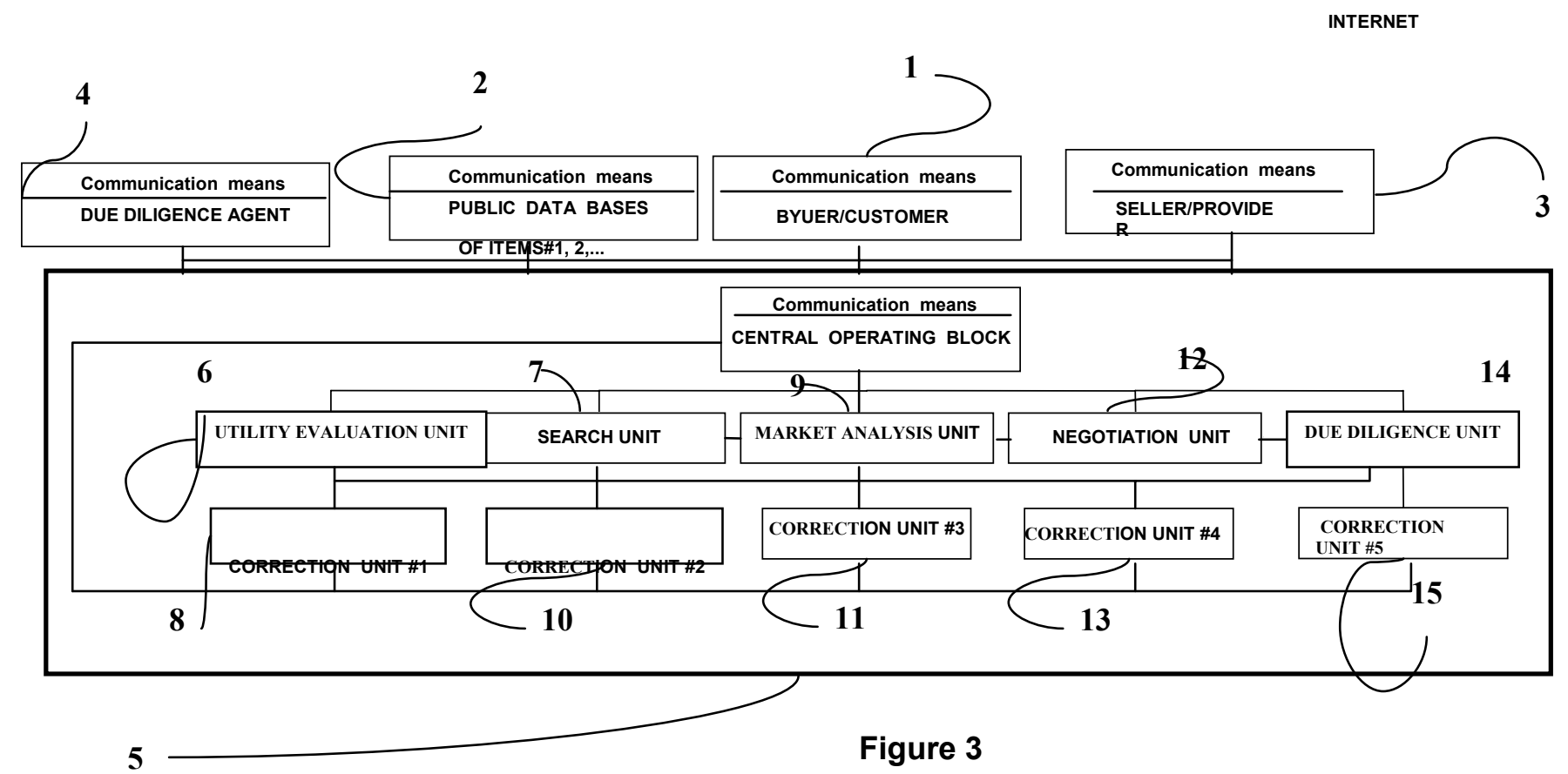

the product/service parameters $\Omega 1$ and in the space of contract terms parameters $\Omega 2$ thus defining the admissible domain for the consecutive search of product/service in question (being the part of the central operating block 5 as it is shown in Figure 3 the utility evaluation unit 6 is programmed to calculate several quantitative characteristics of these preferences);

- $\quad$ the system contacts through the communication means over the Internet all publicly available databases 2 which may contain information about product/service in question and organizes the search of admissible items inside of the search domain defined at the previous step (being the part of the central operating block 5 as it is shown in Figure 3 the search unit 7 is programmed to search said databases and to generate the first list of admissible items in accordance with the buyer's preferences having been formulated on the previous step);

- in the case when said first list contains no items (no admissible items were found) the system returns recurrently to the first step of the whole procedure with the suggestion to change buyer's preferences (to enlarge the search domain) or cancels all procedure if the buyer disagrees with the suggested changes (being the part of the central operating block 5 as it is shown in Figure 3 the first correction unit 8 is programmed to fulfill this step);

- $\quad$ on the basis of information delivered from the publicly available databases 2 the system creates the statistical models of the market situation and tendencies at the proximity of said first list of items including the models of the marginal market evaluations and the models of the prevailing (asking and selling) market contract terms (being the part of the central operating block 5 the market analysis unit 9 is programmed to fulfill this step);

- the system reevaluates the admissible search domain and if the changes are necessary it returns to the step of the search (the market analysis unit 9 is programmed to fulfill this step also);

- the system contacts the potential buyer 1 again with the purpose to inform about the marginal prices of the items' parameters from said first list and about marginal prices of the contract parameters for the same items, and it returns recurrently to the first step of the whole procedure if the buyer considers to change preferences or it confirms the already existing first list of items if the buyer considers not to change preferences (being the part of the central operating block 5 the second correction unit 10 is programmed to fulfill this step); 
- the system eliminates items from said first list which are situated in contradiction with the statistical models of the market situation and tendencies (fair price hypothesis), thus generating the second shorter list of negotiable items (for fulfillment of this step the aforementioned market analysis unit 9 is also responsible);

- in the case when said second list contains no items the system returns recurrently to the first step of the whole procedure with the suggestion to change buyer's preferences (to enlarge the search domain) or to cancel the procedure if the buyer disagrees with the suggested changes (being the part of the central operating block 5 the third correction unit 11 is programmed to fulfill this step);

- after establishing the initial interactive contact with the potential sellers/providers 3 of the items from said second list through the communication means over the Internet the system evaluates their actual preferences in the space of negotiable contract parameters $\Omega 2$ and defines the negotiation domains (for fulfillment of this step the aforementioned utility evaluation unit 6 is responsible);

- the system organizes the processes of simultaneous interactive negotiations at said negotiation domains between buyer 1 and each of said sellers 3 and formulates suggestions that can constitute the basis of compromises for the each pair buyer/seller (being the part of the central operating block 5 the negotiation unit 12 is programmed to fulfill this step);

- the system generates the third list of the items for which the compromises between the buyer 1 and any one of the sellers 3 were agreed upon by both of them and designates the final item from said third list for which the result of the negotiation is best for the buyer; the system obtains the buyer's approval for finalizing the transaction after that (for fulfillment of this step the aforementioned negotiation unit 12 is responsible);

- $\quad$ in the case when said third list contains no items the system returns recurrently to the first step of the whole procedure with the suggestion to change buyer's preferences (to enlarge the search domain) or to cancel the procedure if the buyer disagrees with the suggested changes (being the part of the central operating block 5 the fourth correction unit 13 is programmed to fulfill this step);

- the system generates all necessary legal documents and organizes the processes of due diligence and legal closing thus successfully finishing the procedure (being the part of the central operating block 5 the due diligence unit 14 is programmed to fulfill this step);

- the system returns recurrently to the next item from said third list if the due diligence process had been finished unsuccessfully (being the part of the central operating block 5 the fifth correction unit 15 is programmed to fulfill this step);

- $\quad$ in the case when said third list contains no more items the system returns recurrently to the first step of the whole procedure with the suggestion to change buyer's preferences (to enlarge the search domain) or to cancel the procedure if the buyer disagrees with the suggested changes (for fulfillment of this step the aforementioned fifth correction unit 15 is responsible).

\section{Conclusion}

The introduction of flexibility functions for prospective E-commerce B2B clients delivers a useful approach in resolving multiple complications, that are specific for that new class of business transactions. For commercial real estate transaction to be implemented over the Internet there are some essential features that should be provided by the computer system. That system implements the next main functions:

1. evaluates real preferences of the potential customer (buyer) and defines the admissible search domain;

2. searches all publicly available databases and generates a statistical model of the market situation and tendencies at the market domain relating to the customer's preferences; 
Utility and Flexibility Functions

3. evaluates real preferences of the sellers at the same market domain and defines the admissible negotiation domains;

4. organizes the process of negotiations pertaining to the information received and formulates suggestions that will constitute the basis of a compromise;

5. generates the necessary legal documents and organizes the processes of due diligence and legal closing.

Real flexibility functions of the clients are likely to be complex and dynamic; there are many interacting variables and other influences to be considered in a future research. The use of intelligent systems based on some neural network or on some Bayesian reasoning may become a perspective direction of that research.

\section{References}

Brown, Scott M., Santos, Eugene, Jr., \& Banks, Sheila B. (1998). Utility Theory-Based User Models for Intelligent Interface Agents. Proceedings of the 12th Biennial Conference of the Canadian Society for Computational Studies of Intelligence on Advances in Artificial Intelligence (AI-98), LNAI, Vol. 1418, pp. 378-392, Springer.

Chajewska, Urszula, Koller, Daphne, \& Ormoneit, Dirk. (2001). Learning an Agent's Utility Function by Observing Behavior. Proc. 18th International Conf. on Machine Learning, pp. 35-42, Morgan Kaufmann, San Francisco, CA.

Dearden, A., Harrison, M., \& Wright, P. (2000). Allocation of Function: Scenarios, Context and the Economics of Effort. International Journal of Human-Computer Studies, 52(2), pp. 289-318, 2000.

Fishburn P. (1988). Nonlinear Preference and Utility Theory. The Johns Hopkins University Press, Baltimore.

Giang, Phan H., Shenoy, Prakash P. (2000). A Qualitative Linear Utility Theory for Spohn's Theory of Epistemic Beliefs. Proceedings of the 16th Conference on Uncertainty in Artificial Intelligence (UAI-00), pp. 220-229, Morgan Kaufmann Publishers.

Mendes, Emilia, Mosley, Nile, \&Counsell, Steve (2001). The Cognitive Flexibility Theory: an Approach for Teaching Hypermedia Engineering. Proceedings of the 6th Annual SIGCSE Conference on Innovation and Technology in Computer Science Education (ITiCSE-01), SIGCSE Bulletin, Vol. 33, 3, pp. 21-24, ACM Press.

Mirkin, Boris. (2001). Reinterpreting the Category Utility Function. Machine Learning, 45(2), pp. 219-228, Kluwer Academic Publishers, Boston.

Stavrovski, Boris. (1999). Method and System for Doing Real Estate and other Business over the Internet, that involves Search, Negotiations and Legal Closing. U.S. patent application pending. Ser. No. 09/364.798.

\section{Biography}

Boris Stavrovski, Ph.D., Dr. of Tech. Sciences is a Professor in the College of Staten Island at the City University of New York. He teaches courses on IT and is conducting research on methodical innovations for E-Commerce. 